All things considered, Geng and colleagues' proposal is probably the best current hypothesis to explain the observed changes in oxidant levels.

The new results highlight once again how little we understand about the complexity of chemistry-climate feedbacks and, more generally, of how strongly Earth-system processes are interconnected. Tropospheric composition is driven in different ways by the ocean, cryosphere (the part of the Earth system that is frozen water), lithosphere (Earth's rocky, outermost shell) and the land and marine biospheres, but also by the stratosphere. It will be crucial to develop a better understanding of the feedback mechanisms involved to more accurately predict how anthropogenic emissions might affect climate and air quality in the future. In particular, a deeper understanding of how atmospheric composition - especially the lifetime of greenhouse gases - is affected by climate change will be important when using results from climate models to inform policy decisions about how global warming can be kept below certain temperature targets.

A new generation of Earth-system models encompassing all of the processes and feedbacks that determine climate - including those associated with the stratosphere - will be needed to answer questions of how atmospheric composition and climate interact. Simulations should not simply be 'tuned' to provide the best reproduction of the present climate, but should be built on an understanding of the processes involved, to allow the credible simulation of both past and present climates. Most crucially, these models should be compared continuously with observations and with proxy palaeoclimate data, to test their validity and to inform further development. This, in turn, will require strong collaboration between modellers and data-collecting scientists, and will need palaeoclimate researchers to join their expertise with that of experts studying present and future climate.

Michaela I. Hegglin is in the Department of

Meteorology, University of Reading,

Reading RG6 6BX, UK.

e-mail:m.i.hegglin@reading.ac.uk

1. Prinn, R. G. Annu. Rev. Environ. Resour. 28, 29-57 (2003).

2. Lelieveld, J., Peters, W., Dentener, F. J. \& Krol, M. C. J. Geophys. Res. 107, 4715 (2002).

3. Geng, L. et al. Nature 546, 133-136 (2017).

4. Montzka, S. A. et al. Science 331, 67-69 (2011).

5. Alexander, B. \& Mickley, L. J. Curr. Pollut. Rep. 1, 57-69 (2015)

6. Murray, L. T. et al. Atmos. Chem. Phys. 14, 3589-3622 (2014).

7. Peñuelas, J. \& Staudt, M. Trends Plant Sci. $\mathbf{1 5}$, 133-144 (2010).

8. Hegglin, M. I. \& Shepherd, T. G. Nature Geosci. 2, 687-691 (2009).

9. Zeng, G., Morgenstern, O., Braesicke, P. \& Pyle, J. A. Geophys. Res. Lett. 37, L09805 (2010).

10.Schmidt, J. A. et al. J. Geophys. Res. Atmos. 121, 11819-11835 (2016)

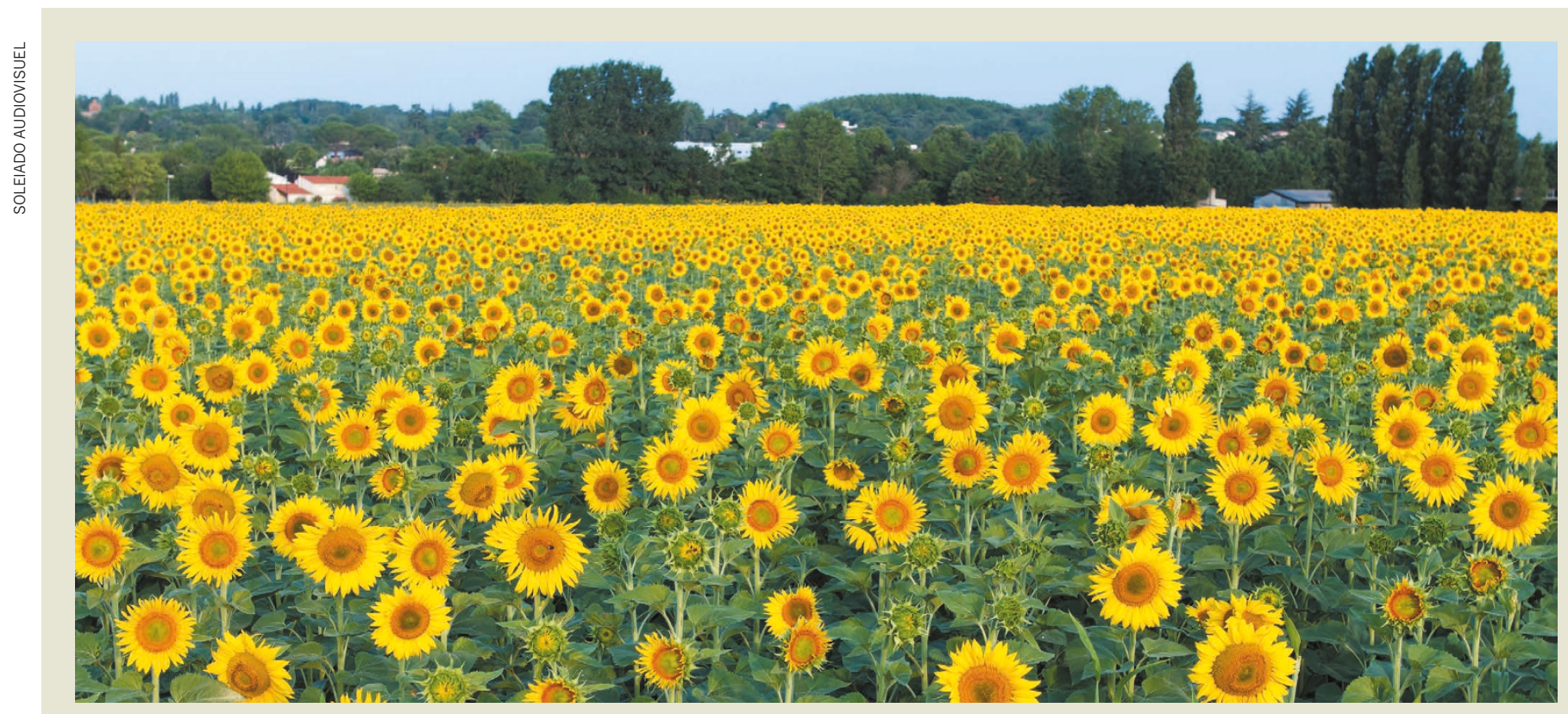

GENOMICS

\section{Sunflowers sequenced}

Sunflowers are a major global crop, producing seeds and oil. In addition, they maintain stable yields under a wide range of environmental conditions, including drought - a useful attribute in a changing climate. On page 148, Badouin et al. report a reference genome for the domesticated sunflower Helianthus annuus L. (H. Badouin et al. Nature 546, 148-152; 2017).

The genome of the sunflower (pictured) has proved difficult to assemble, because it is large (3.6 gigabase long) and highly repetitive. Badouin and colleagues overcame these hurdles using an approach that included single-molecule real-time sequencing of long stretches of DNA, enabling the many similar and related sequences to be pieced together. The authors compared the genome with those of related plants, to trace the sunflower's complex evolutionary history. They identified whole-genome duplication events that had occurred in sunflowers alone or also in several other Asterids - a family of flowering plants that, in addition to sunflowers, includes lettuce, artichoke and coffee.

The researchers then resequenced, at lower coverage, 80 cultivated lines of sunflower, to characterize their genetic diversity and to help identify the genetic basis of agriculturally relevant traits. By carrying out genome-wide association analyses using additional lines, they identified 35 genomic regions associated with flowering time.

Finally, Badouin et al. characterized the gene-expression profiles of sunflower roots, stems, leaves and floral organs, and those of leaves and roots treated with hormones or exposed to stressors such as drought. They then integrated these data into models of the genetic networks that regulate flowering time, seed oil content and quality, which they constructed using information from related plants. The analysis identified both new and previously known candidate genes for each trait, and will be a useful resource for breeding programmes to improve sunflower resilience and oil production. Orli G. Bahcall 